\title{
Genomics-Metabolomics Profiling Disclosed Marine Vibrio spartinae 3.6 as a Producer of a New Branched Side Chain Prodigiosin
}

Giovanni Andrea Vitale,,$^{\dagger}$ Martina Sciarretta, ${ }^{\dagger}$ Fortunato Palma Esposito, ${ }^{\dagger}, \S$ Grant Garren January, ${ }^{\dagger}$ Marianna Giaccio, ${ }^{\dagger}$ Boyke Bunk, ${ }^{\perp}$ Cathrin Spröer, ${ }^{\perp}$ Felizitas Bajerski, ${ }^{\perp}$ Deborah Power, $\|$ Carmen Festa, ${ }^{\star}$ Maria Chiara Monti, $\nabla$ Maria Valeria D’Auria*, ${ }^{\ddagger}$ Donatella de Pascale*. $^{\dagger} \S$

${ }^{\dagger}$ Institute of Biochemistry and Cellular Biology, National Research Council (IBBC-CNR), Via Pietro Castellino 111, I-80131 Naples, Italy.

\$ Department of Pharmacy, University of Naples "Federico II" (UNINA), Via Domenico Montesanto, 49, I-80131 Naples, Italy.

$\S$ Stazione Zoologica Anton Dohrn (SZN), Villa Comunale di Napoli, I-80121 Naples, Italy.

$\perp$ Leibniz Institute DSMZ-German Collection of Microorganisms and Cell Cultures GmbH, Inhoffenstraße 7B, 38124 Braunschweig, German

॥ Centro de Ciencias do Mar (CCMAR), Universidade do Algarve Campus de Gambelas, 8005-139 Faro, Portugal

$\nabla$ Department of Pharmacy, University of Salerno, (UNISA) I-84084 Fisciano, SA, Italy 


\section{Contents}

Table S1. Environmental features of the collecting points in Ria Formosa lagoon

Table S2. Results of the prescreening for the antimicrobial activity against four target pathogens

Table S3. Pathogenic strains and positive controls used for the antimicrobial assay

Figure S1. Prodigiosin biosynthesis prediction from Vibrio spartinae 3.6 genome S4

Figure S2. Linear display of Prodigiosin biosynthetic gene cluster in $V$.

spartinae 3.6

Figure S3. Prediction of Vspart_02107 topology

Figure S4. Chiral HPLC trace of cycloprodigiosin 2

\section{Spectral data of new isoheptylprodigiosin (5)}

HRESI-MS spectrum of compound $\mathbf{5}$

HRESI-MS $^{\mathrm{n}}$ spectra of compound $\mathbf{5}$ S7

UV spectrum of compound $\mathbf{5}$ S8

${ }^{1} \mathrm{H}-\mathrm{NMR}$ spectrum of compound 5 S9

COSY spectrum of compound $\mathbf{5}$ S9

HSQC spectrum of compound $\mathbf{5}$

\section{Spectral data of other compounds}

HRESI-MS spectrum of cycloprodigiosin 2

HRESI-MS ${ }^{2}$ spectrum of cycloprodigiosin 2

HRESI-MS ${ }^{2}$ spectrum of cycloprodigiosin 2 - low $\mathrm{m} / \mathrm{z}$ portion $\quad \mathrm{S} 12$

$\begin{array}{ll}\text { HRESI-MS spectrum of peak C } & \text { S12 }\end{array}$

$\begin{array}{ll}\text { HRESI-MS } & 2 \\ \text { spectrum of peak C } & \text { S13 }\end{array}$

HRESI-MS ${ }^{2}$ spectrum of peak C - low $\mathrm{m} / \mathrm{z}$ portion $\quad \mathrm{S} 13$

$\begin{array}{ll}\text { HRESI-MS }^{3} \text { spectrum of peak C } & \text { S14 }\end{array}$

$\begin{array}{ll}\text { HRESI-MS spectrum of peak E } & \text { S14 }\end{array}$

$\begin{array}{ll}\text { HRESI-MS }^{2} \text { spectrum of peak E } & \text { S15 }\end{array}$

HRESI-MS ${ }^{2}$ spectrum of peak E - low $\mathrm{m} / \mathrm{z}$ portion $\quad \mathrm{S} 15$

$\begin{array}{ll}\text { HRESI-MS } & 3 \\ \text { spectrum of peak E } & \text { S16 }\end{array}$

Table S4. ${ }^{1} \mathrm{H}$ NMR data of compounds $\mathbf{1}, \mathbf{2}, \mathbf{3}, \mathbf{4} \quad$ S17 
Table S1. Environmental features of the collecting points in the Ria Formosa lagoon

\begin{tabular}{|c|c|c|c|c|c|c|c|c|c|c|c|c|}
\hline Collecting point & \multicolumn{2}{|c|}{ GPS coordinates } & \multicolumn{6}{|c|}{ Sediment } & Depth (m) & $\mathbf{T}\left({ }^{\circ} \mathrm{C}\right)$ & pH & Sal (PSU) \\
\hline Ria Formosa 1 & N 37.00065 & W 007.83401 & $1 \mathrm{~A}$ & $1 \mathrm{~B}$ & $2 \mathrm{~A}$ & $2 B$ & $3 \mathrm{~A}$ & $3 \mathrm{~B}$ & 4 & 21,4 & 7,5 & 35,08 \\
\hline Ria Formosa 2 & N 36.97578 & W 007.88266 & $4 \mathrm{~A}$ & $4 \mathrm{~B}$ & $5 \mathrm{~A}$ & $5 \mathrm{~B}$ & $6 \mathrm{~A}$ & $6 \mathrm{~B}$ & 5,5 & 20,2 & 7,3 & 34,93 \\
\hline Ria Formosa 3 & N36.99151 & W 007.90917 & $7 \mathrm{~A}$ & $7 \mathrm{~B}$ & $8 \mathrm{~A}$ & $8 \mathrm{~B}$ & $9 \mathrm{~A}$ & $9 \mathrm{~B}$ & 6 & 21 & $7-7,5$ & 35,16 \\
\hline Ria Formosa 4 & N 37.01577 & W 008.00505 & $10 \mathrm{~A}$ & $10 \mathrm{~B}$ & $11 \mathrm{~A}$ & $11 \mathrm{~B}$ & $12 \mathrm{~A}$ & $12 \mathrm{~B}$ & 2 & 23,3 & 8,4 & 35,76 \\
\hline
\end{tabular}

Table S2. Results of the prescreening of the antimicrobial activity against four target pathogens

\begin{tabular}{cccccc}
\hline & & \multicolumn{4}{c}{ Pathogenic strains $^{\mathbf{a}}$} \\
\hline Strain code & Growth media & A. baumannii 13 & E. coli ATCC 25922 & S. aureus 6538P & P. aeruginosa PA01 \\
\hline 1.11 & Modified MB & + & + & - & - \\
1.13 & Modified MB & + & $+/-$ & - & - \\
2.12 & Modified MB & + & + & + & - \\
3.6 & Modified MB & + & + & ++ & - \\
4.3 & Modified MB & $+/-$ & $+/-$ & + & - \\
a "+" indicate the presence of an activity halo on the plate, "+/_" the presence of a small halo and "-" the total absence of \\
inhibition.
\end{tabular}

Table S3. Pathogenic strains and positive controls used for the antimicrobial assay

\begin{tabular}{cc}
\hline Bacterial strain & Positive control $^{\mathbf{a}}$ \\
\hline Staphylococcus aureus ATCC 29213 & Vankomycin \\
Staphylococcus aureus ATCC 23235 & Vankomycin \\
Staphylococcus aureus ATCC 6538P & Vankomycin \\
Staphylococcus epidermidis ATCC 35984 & Vankomycin \\
Listeria monocytogenes MB677 & Ampicillin \\
Stenotrophomonas maltophilia ATCC 13637 & Chloramphenicol \\
Stenotrophomonas maltophilia ATCC 13636 & Chloramphenicol \\
Stenotrophomonas maltophilia ATCC 700475 & Chloramphenicol
\end{tabular}




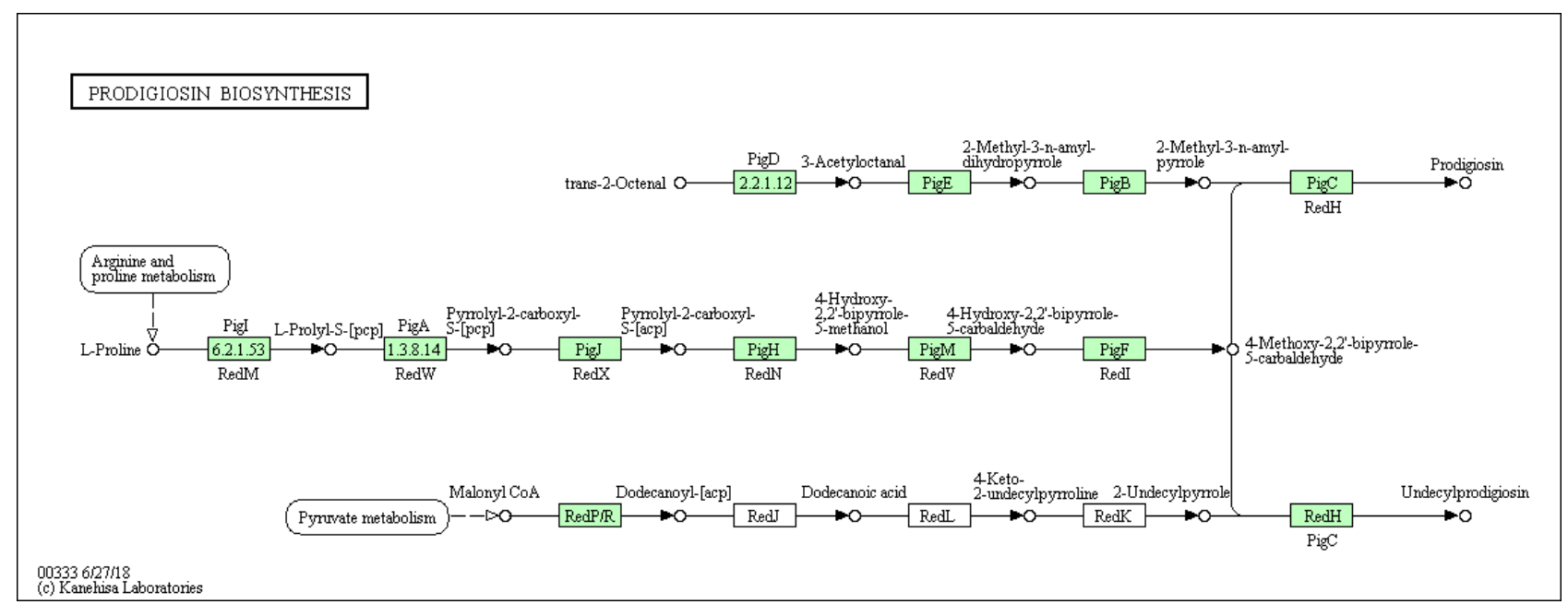

Figure S1. Prodigiosin biosynthesis prediction from Vibrio spartinae 3.6 genome using KEGG BlastKoala

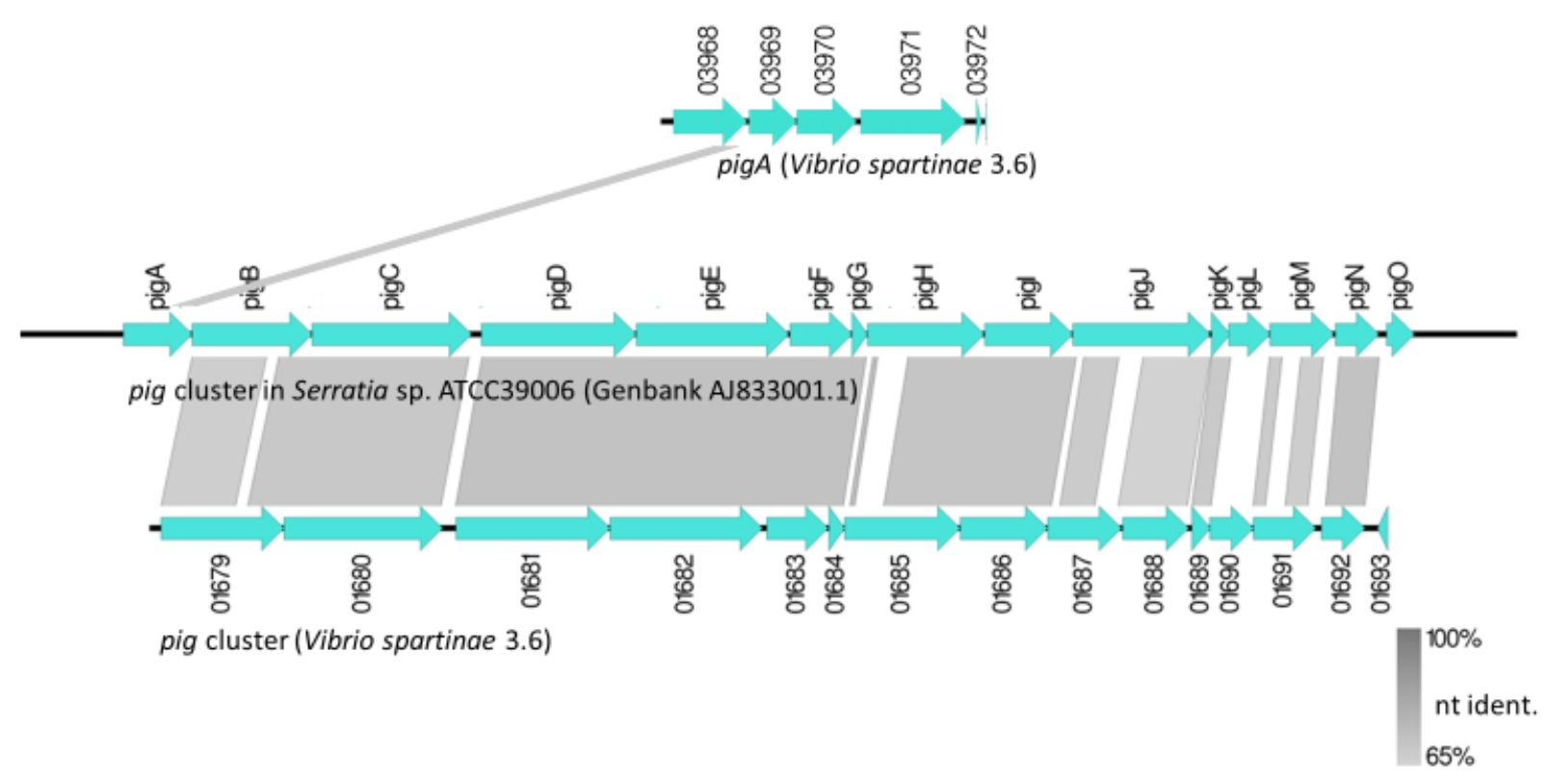

Figure S2. Linear display of Prodigiosin biosynthetic gene cluster in $V$. spartinae 3.6: The complete gene cluster pigB-pigN is present within $V$. spartinae 3.6 on the main chromosome with the exception of pigJ, which is constituting of a $\mathrm{N}$ - and C-terminal fragment. pig $O$ is missing in $V$. spartinae 3.6 while pigA displays C-terminal homology to Vspart_03968 on the second (smaller) chromosome. 


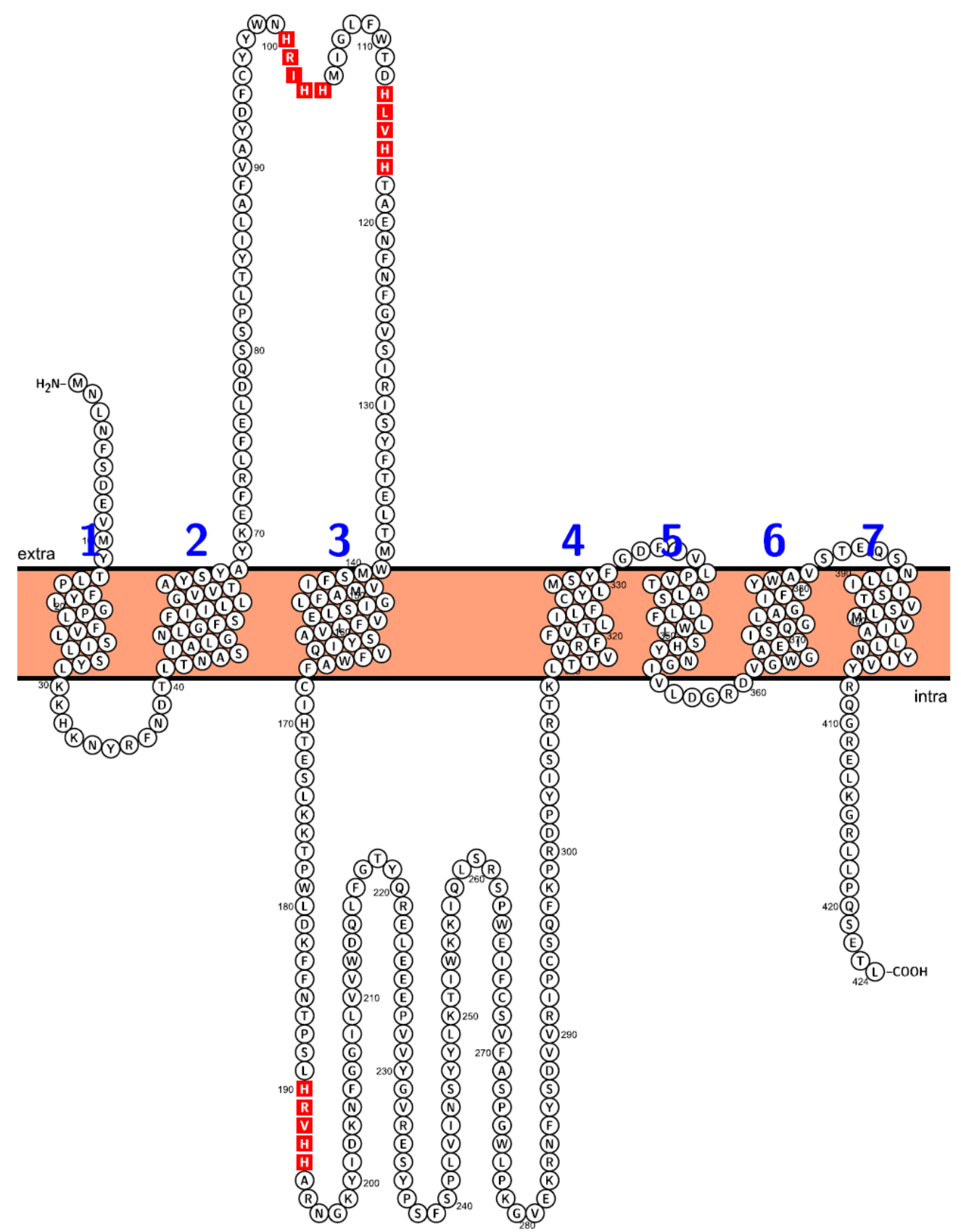

Figure S3. Prediction of Vspart_02107 topology. The transmembrane domains were predicted utilising Phobius ${ }^{1}$ and the imagine was generated with Protter. ${ }^{2}$ In red is highlighted the conserved histidine motif observed in many di-iron oxygenases. ${ }^{3,4}$

(1) Käll, L.; Krogh, A.; Sonnhammer, E. L. J. Mol. Biol. 2004, 338, 1027-1036.

(2) Omasits, U.; Ahrens, C. H.; Müller, S.; Wollscheid, B. Bioinformatics 2013, 30, 884-886.

(3) Shanklin, J.; Guy, J. E.; Mishra, G.; Lindqvist, Y. J. Biol. Chem. 2009, 284, 18559-18563.

(4) Bai, Y.; McCoy, J. G.; Levin, E. J.; Sobrado, P.; Rajashankar, K. R.; Fox, B. G.; Zhou, M. Nature 2015, 524, 252-256. 


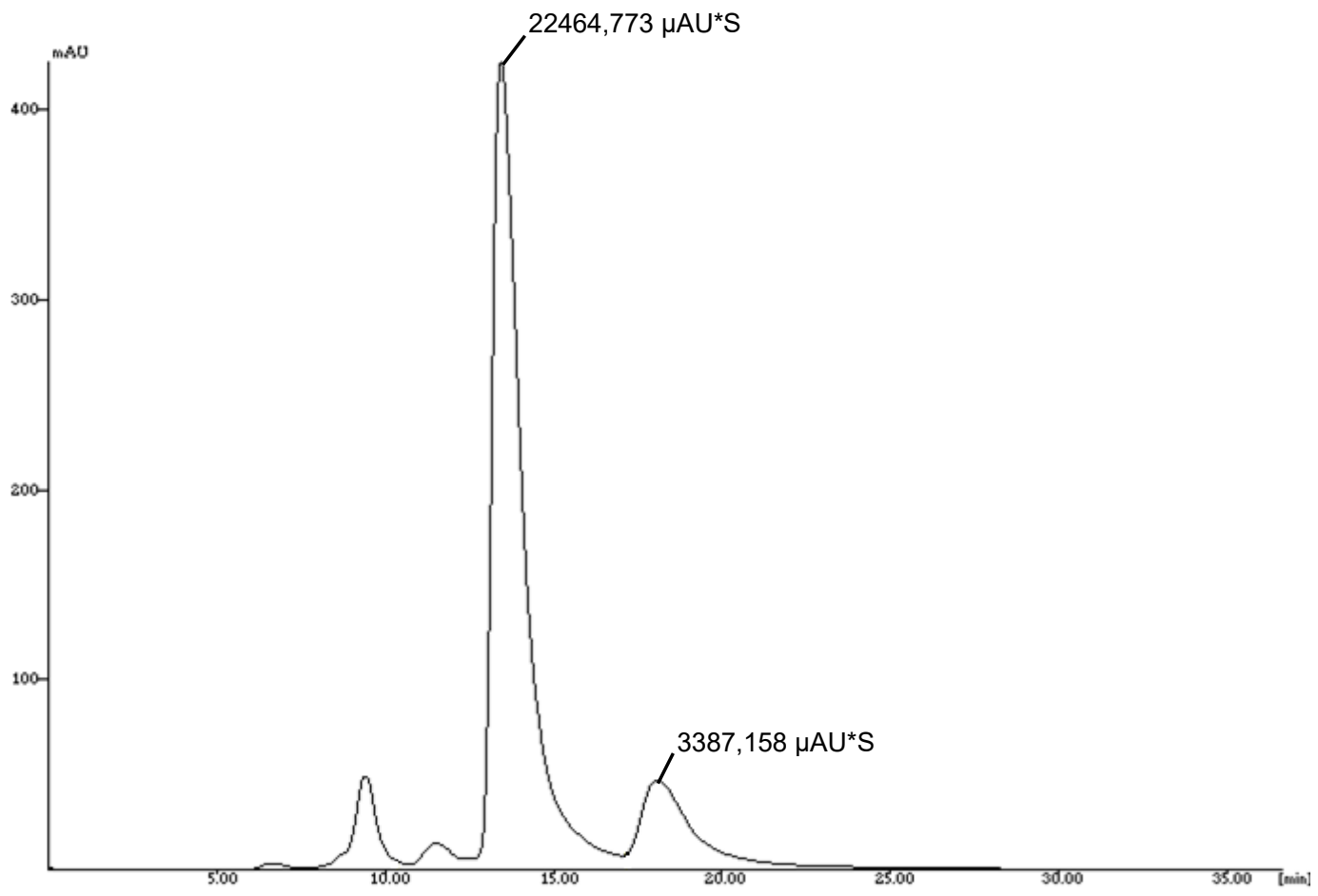

Figure S4. Chiral HPLC trace of cycloprodigiosin 2. Retention time: $13.2 \mathrm{~min}, 18.5 \mathrm{~min}$. 87:13 er. An analytic sample of cycloprodigiosin 2 was subjected to chiral HPLC fractionation on a Phenomenex Lux column (Amylose-2, $5 \mu \mathrm{m} 250$ x $4.6 \mathrm{~mm}$ i.d) using hexane:isopropanol 70:30 and $0.1 \%$ diethylamine as eluent and monitoring the absorbance at $500 \mathrm{~nm}$ (flow rate $0.3 \mathrm{~mL} / \mathrm{min} ; 50$ $\mu \mathrm{L}$ injection volume). The identity of the two peaks was established by ESI MS analysis: $\mathrm{m} / \mathrm{z}$ 322.26 


\section{Spectral data of new isoheptylprodigiosin (5)}

HRESI-MS spectrum of compound $\mathbf{5}$

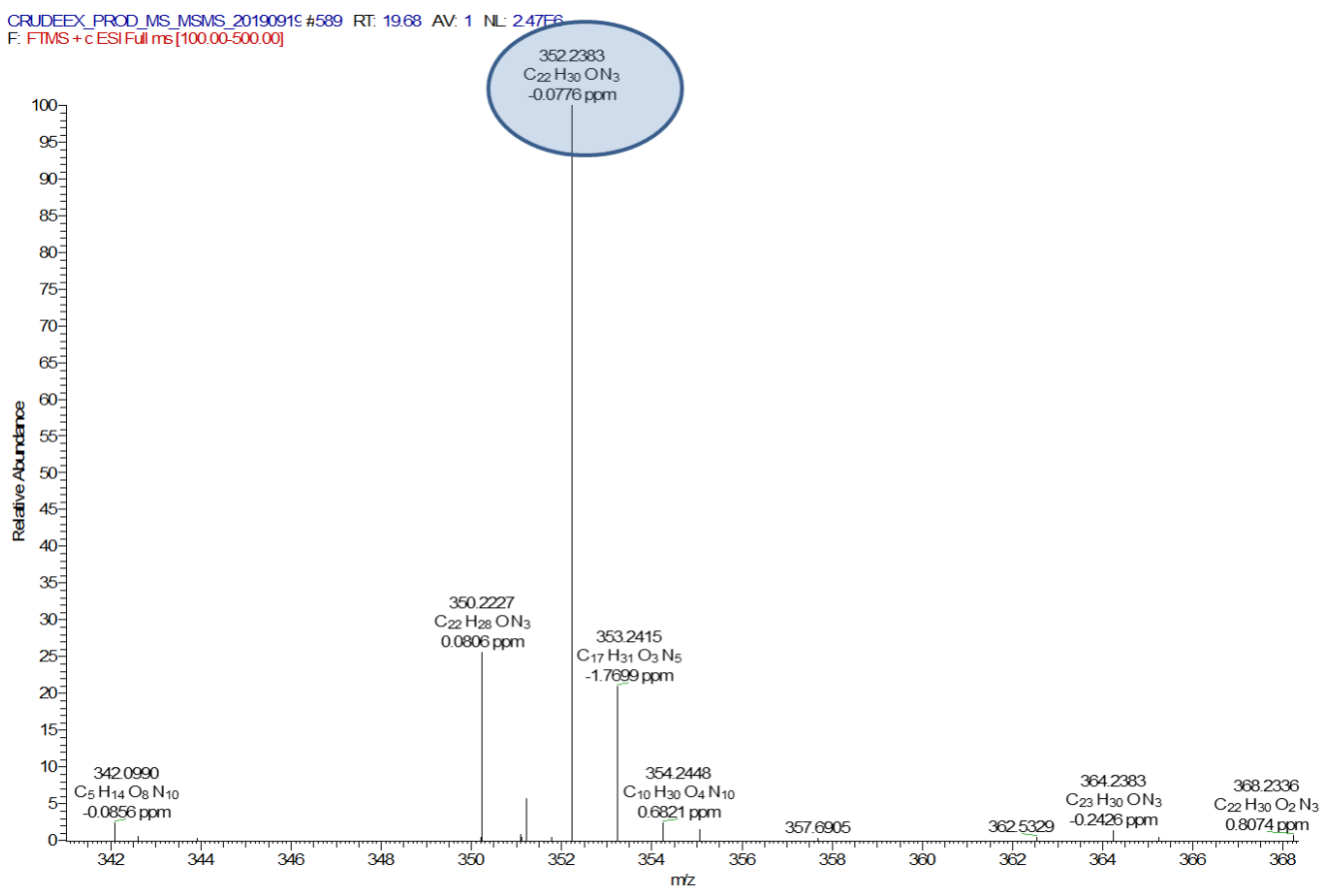

HRESI-MS $^{\mathrm{n}}$ spectra of compound $\mathbf{5}$

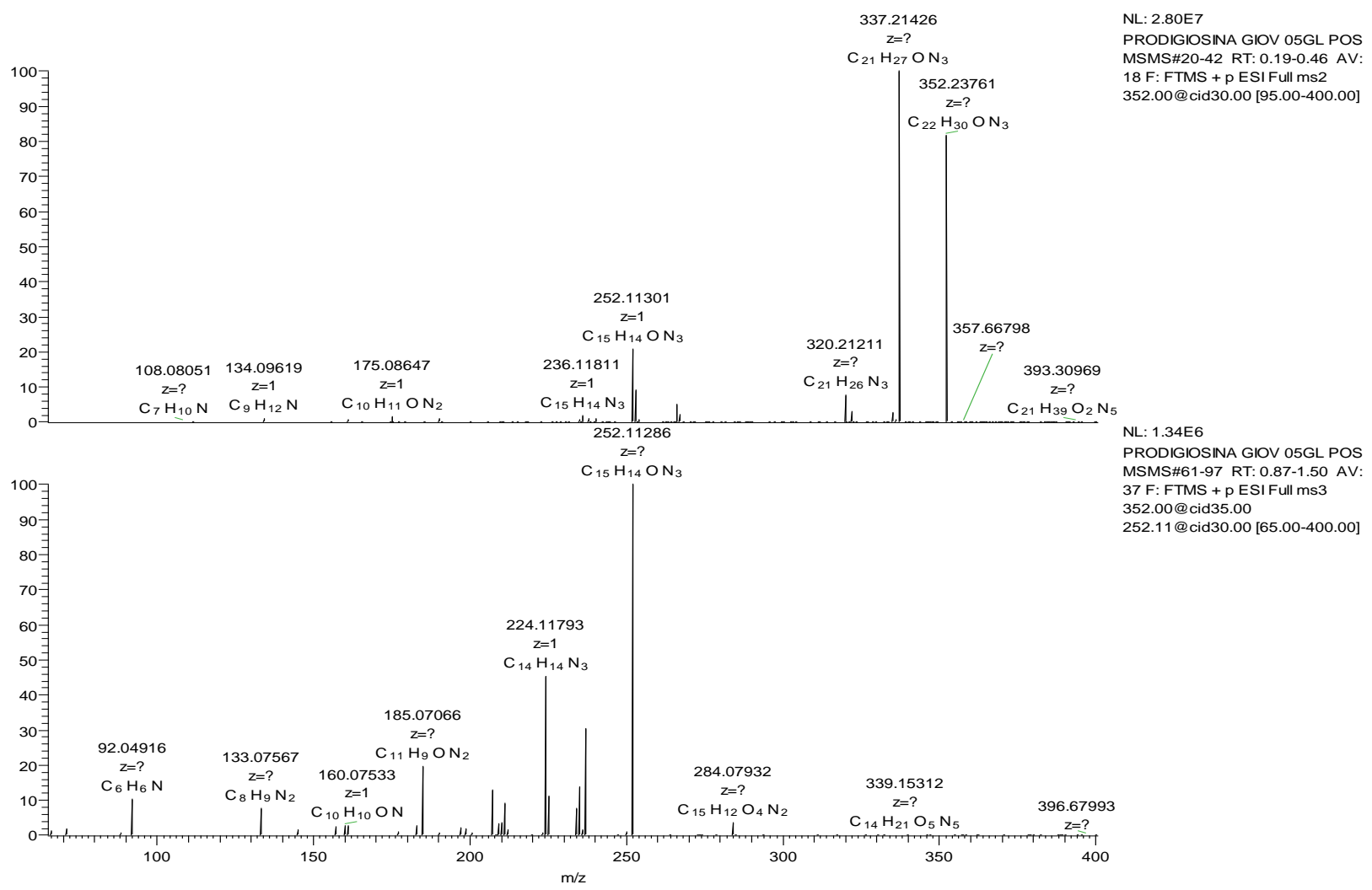


UV spectrum of compound $5(\mathrm{MeOH}+\mathrm{TFA} 0.1 \%$, room temperature $)$

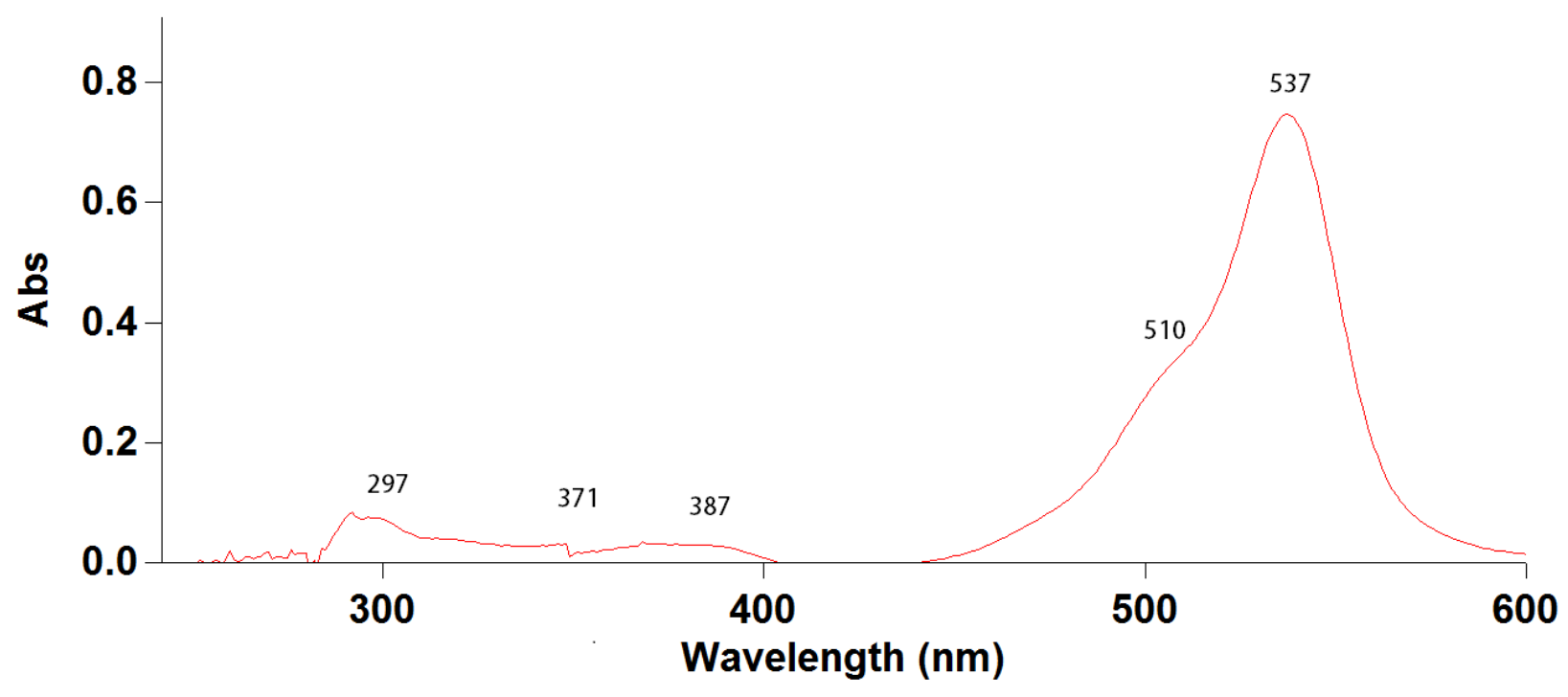


${ }^{1} \mathrm{H}-\mathrm{NMR}$ spectrum of compound $5\left(\mathrm{CDCl}_{3}, 400 \mathrm{MHz}\right)$

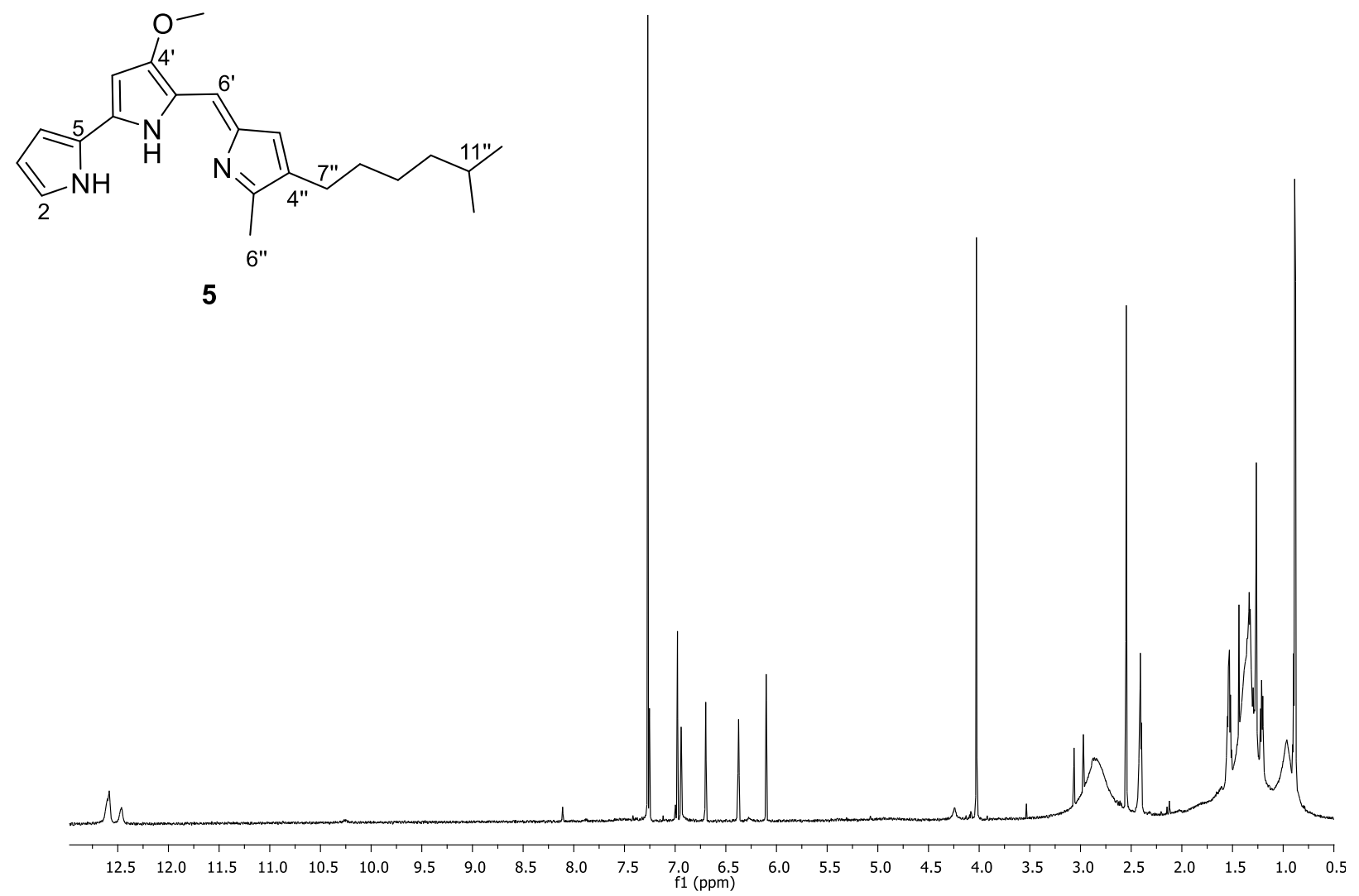

COSY spectrum of compound $5\left(\mathrm{CDCl}_{3}, 400 \mathrm{MHz}\right)$

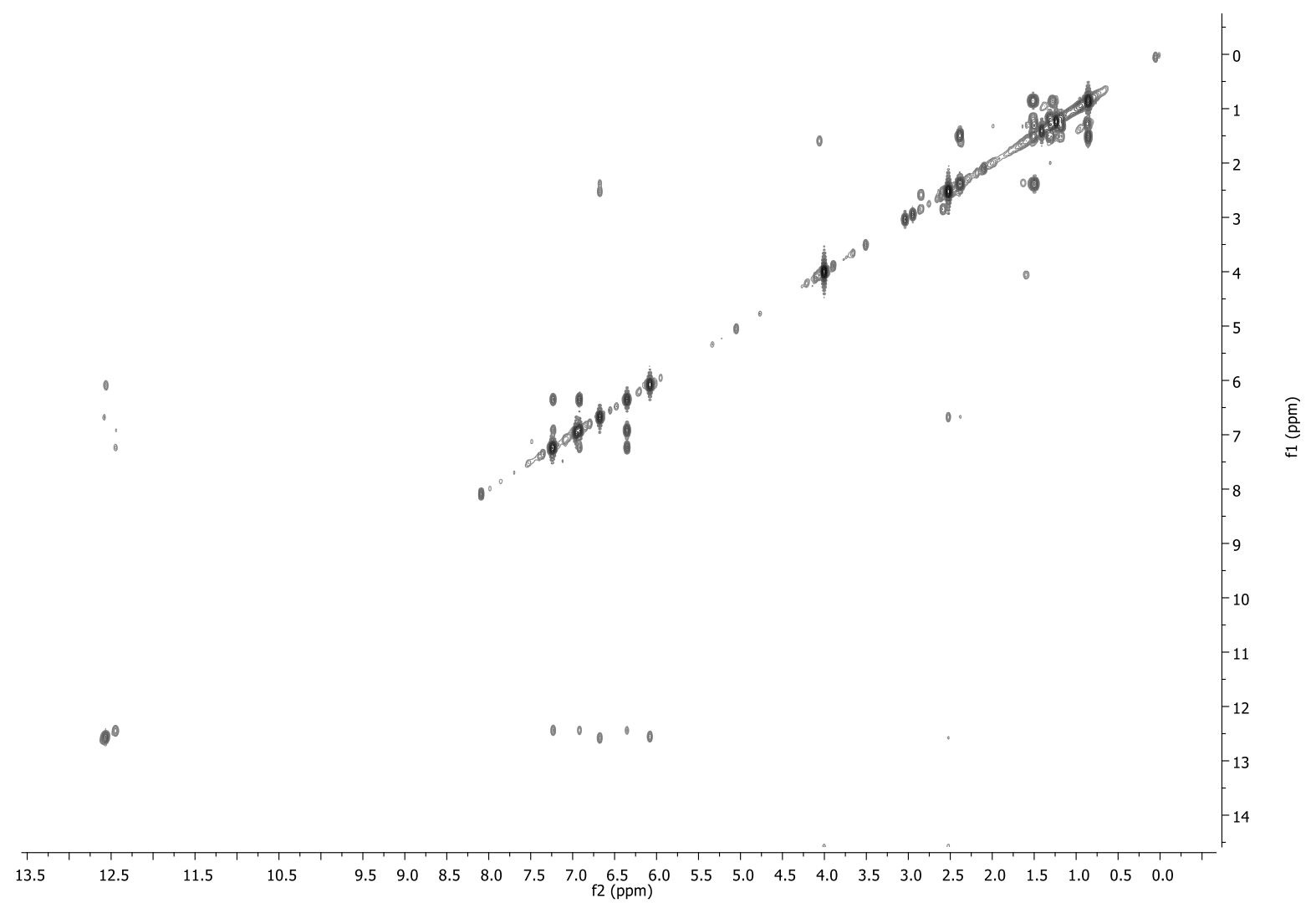


HSQC spectrum of compound $5\left(\mathrm{CDCl}_{3}, 400 \mathrm{MHz}\right)$

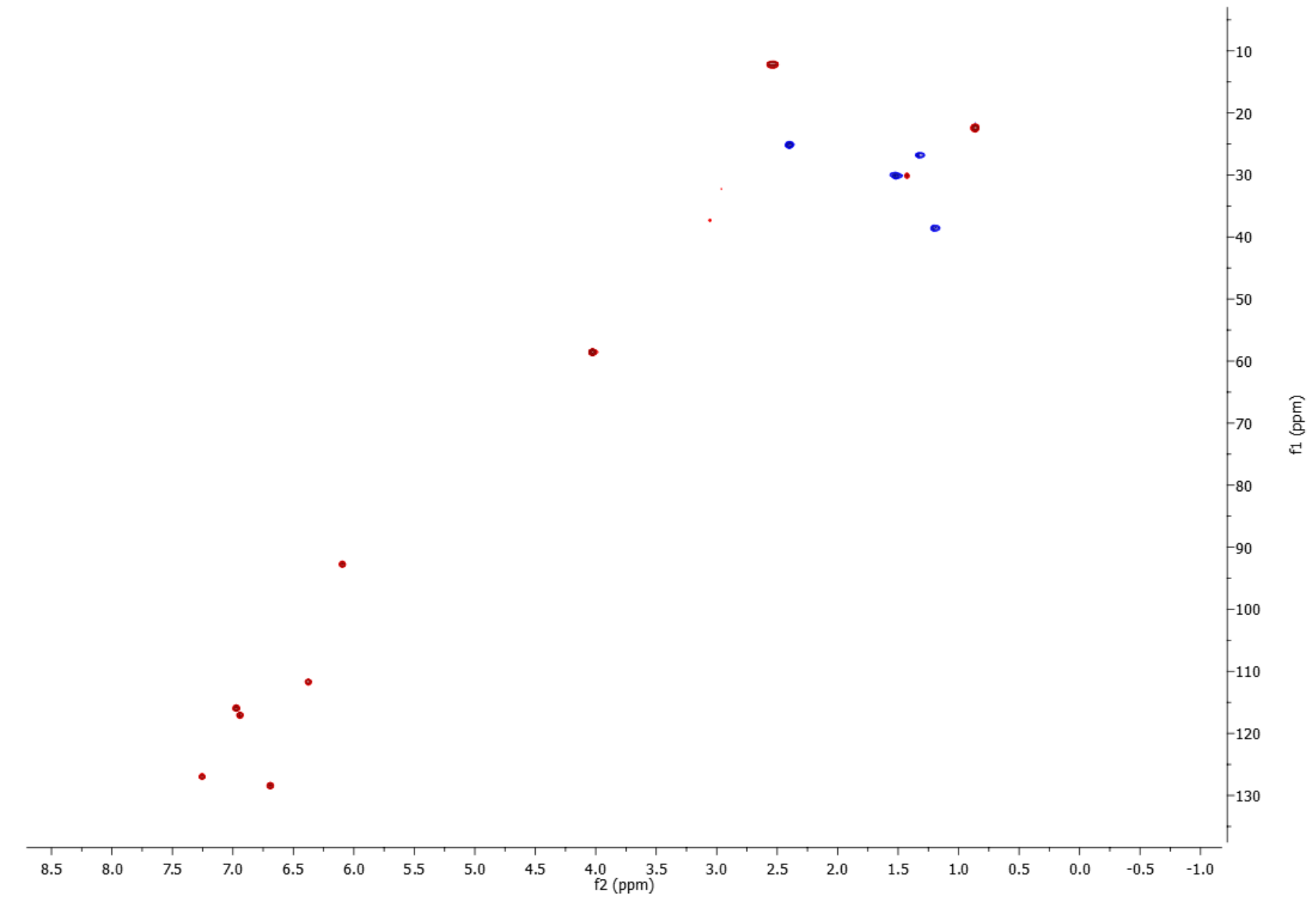




\section{Spectral data of other compounds}

HRESI-MS spectrum of cycloprodigiosin 2

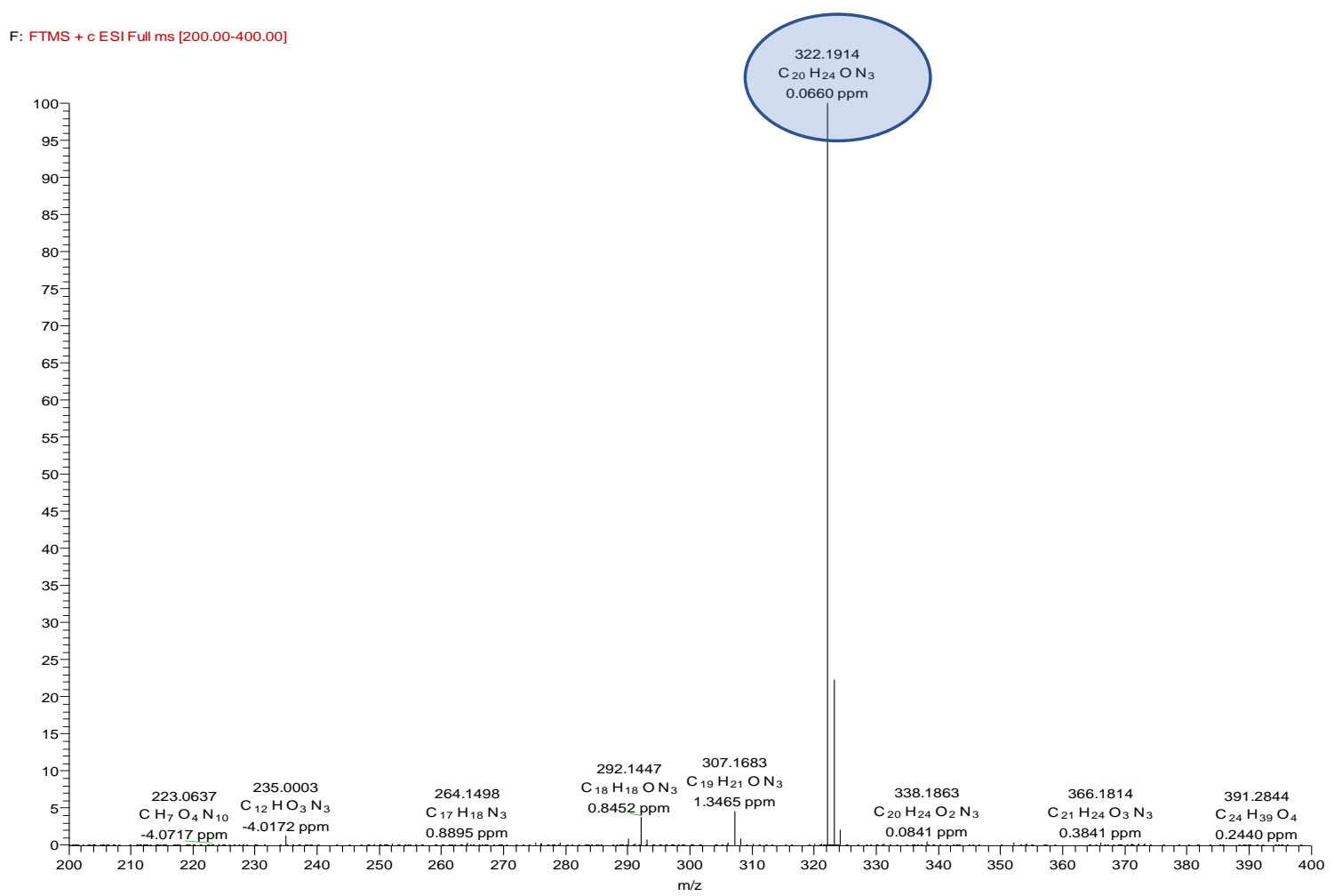

HRESI-MS ${ }^{2}$ spectrum of cycloprodigiosin 2

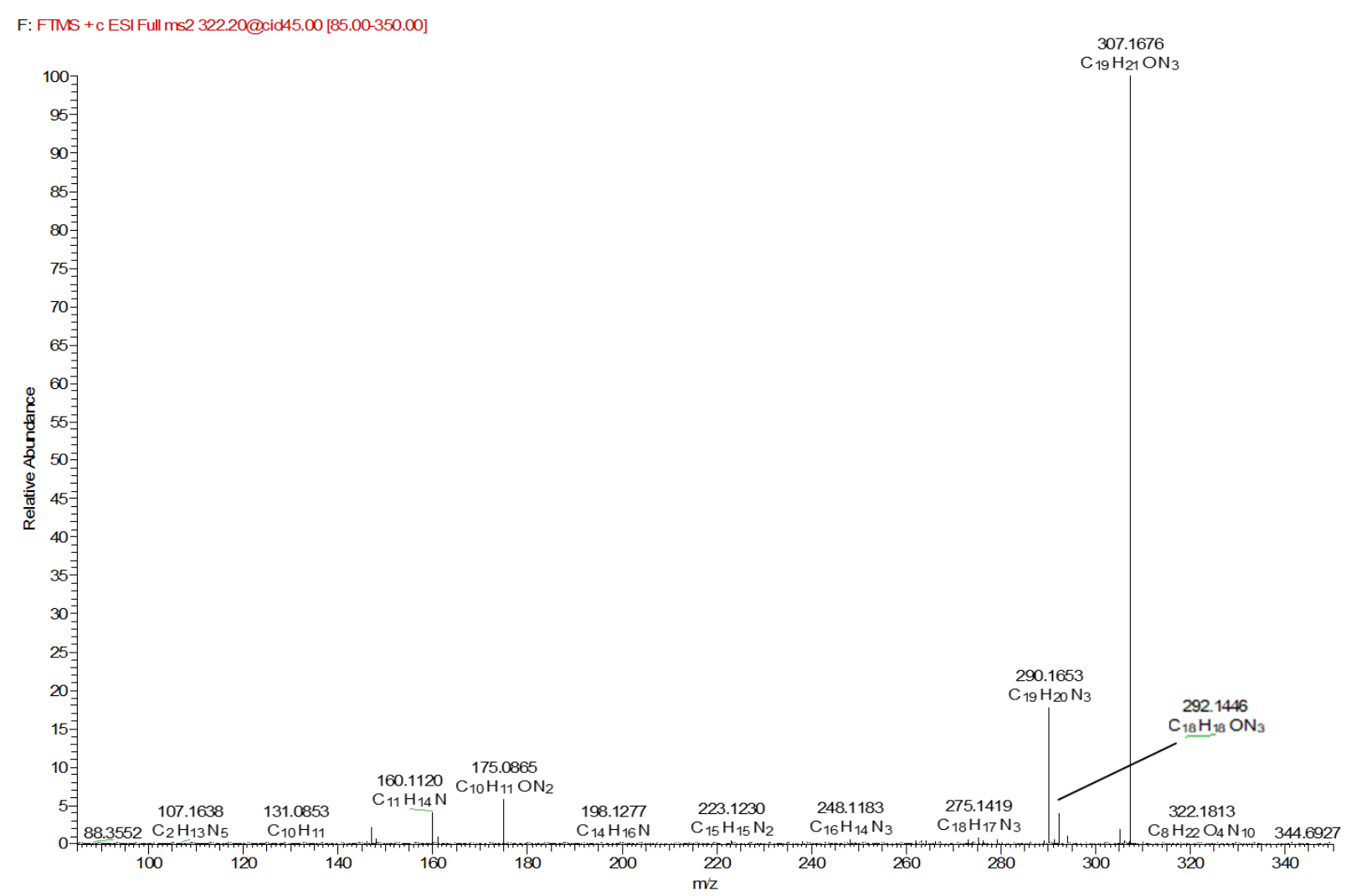


HRESI-MS $^{2}$ spectrum of cycloprodigiosin 2 - low $\mathrm{m} / \mathrm{z}$ portion.

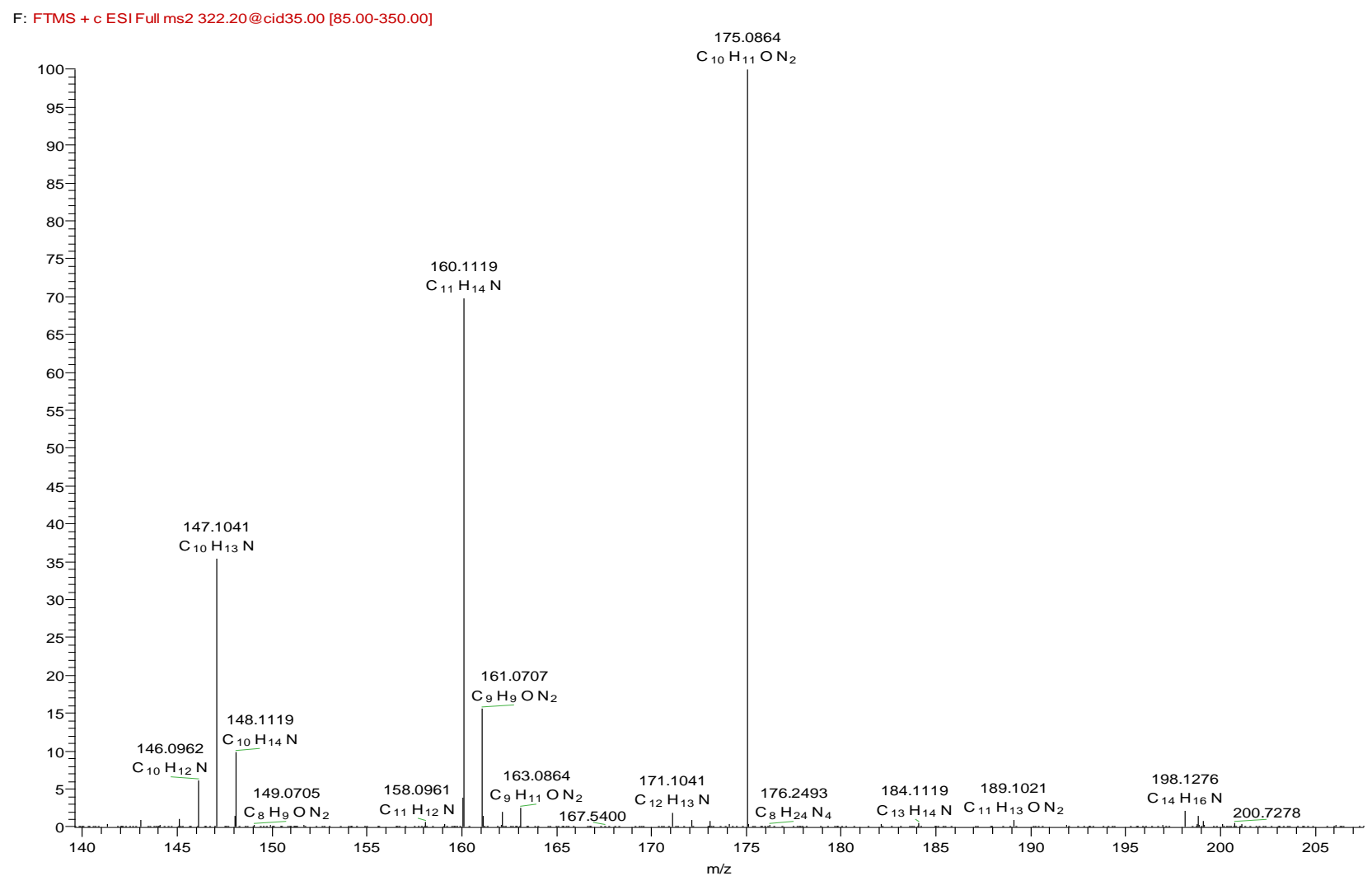

\section{HRESI-MS spectrum of peak C}

F: FTMS + $+\bar{c}$ ESI Fül ms $[200.00-400.00]$
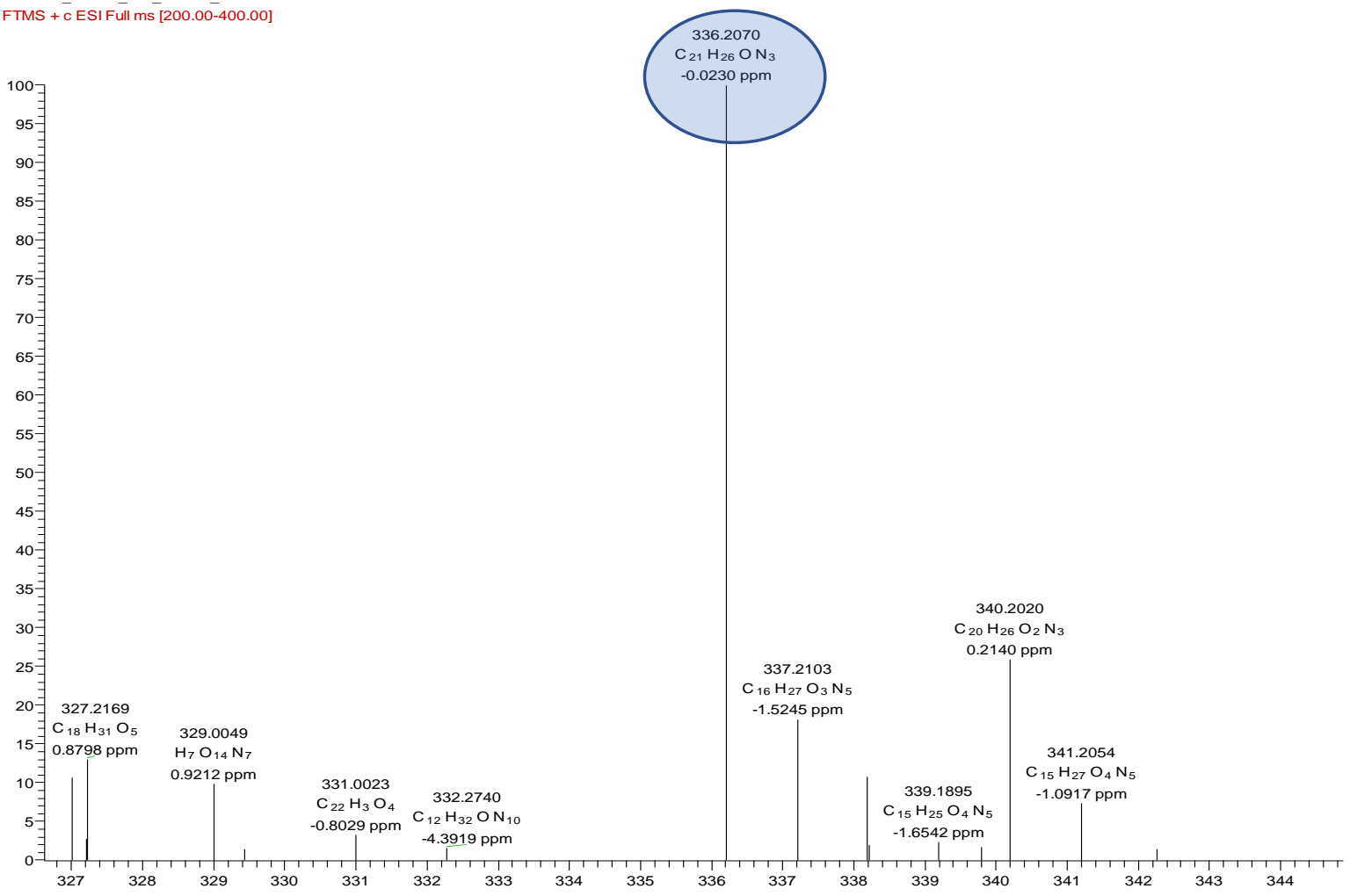
HRESI-MS ${ }^{2}$ spectrum of peak C

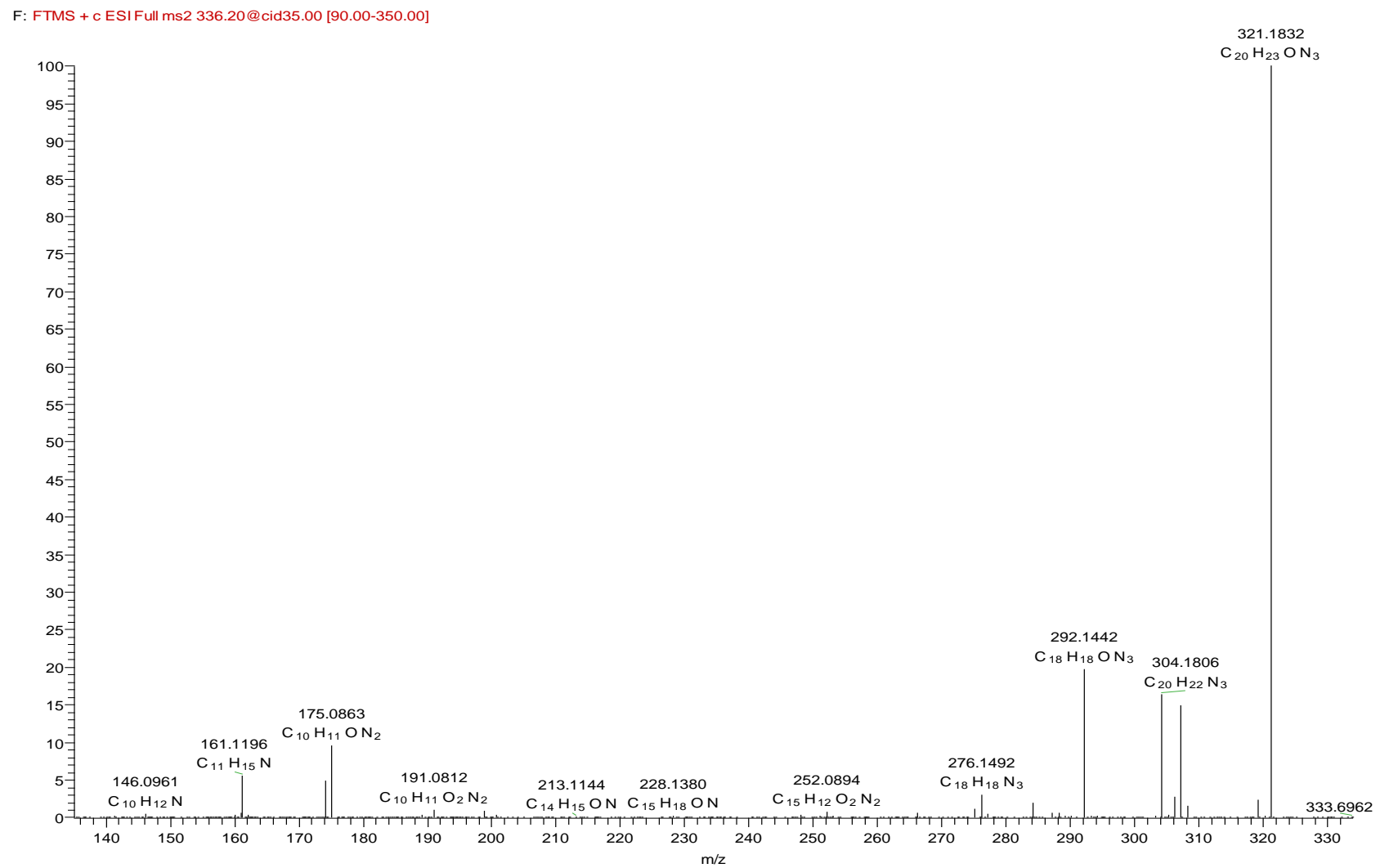

HRESI-MS ${ }^{2}$ spectrum of peak C - low $\mathrm{m} / z$ portion.

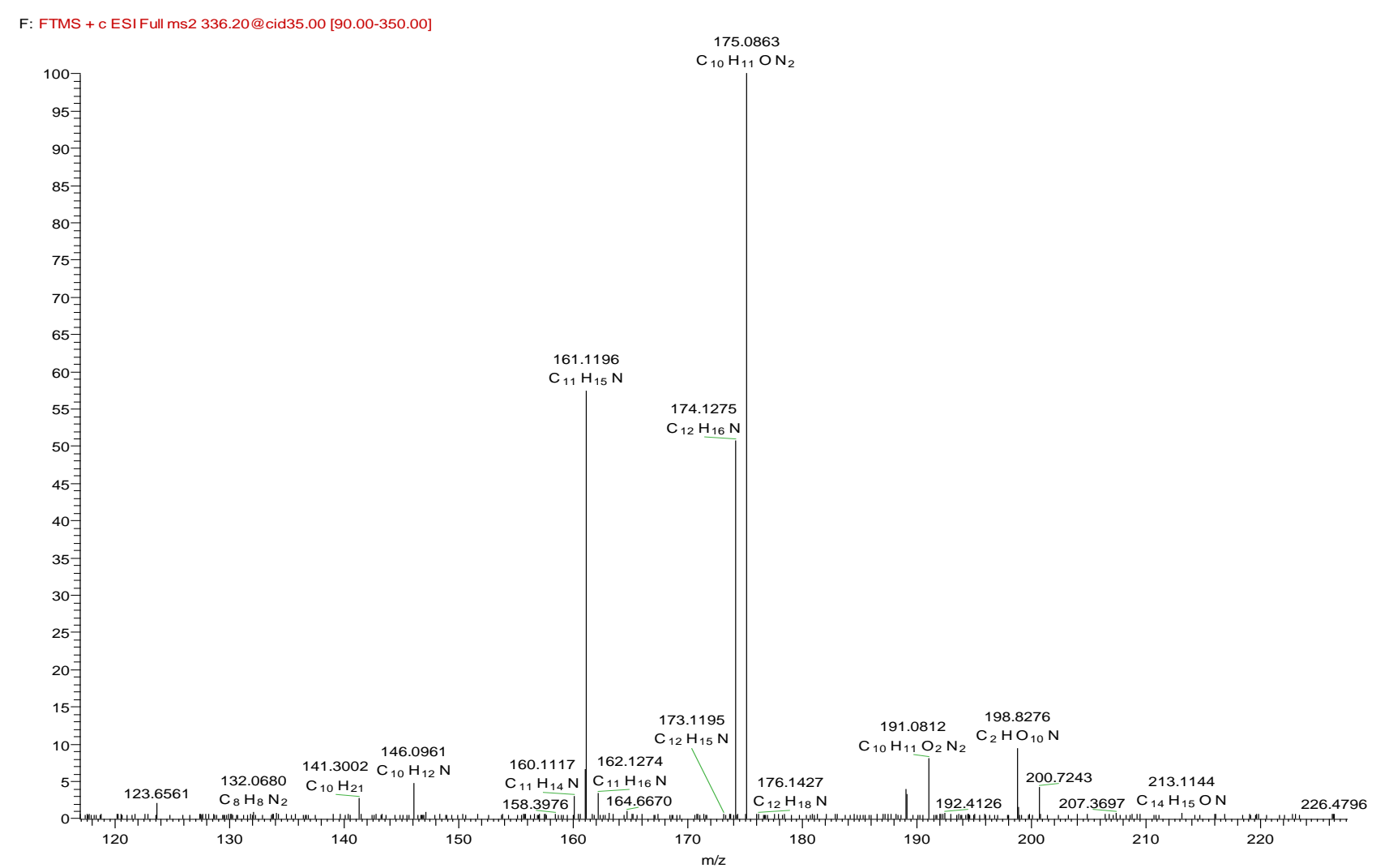


HRESI-MS ${ }^{3}$ spectrum of peak C (from Fragment A, $m / z$ 174.1275)

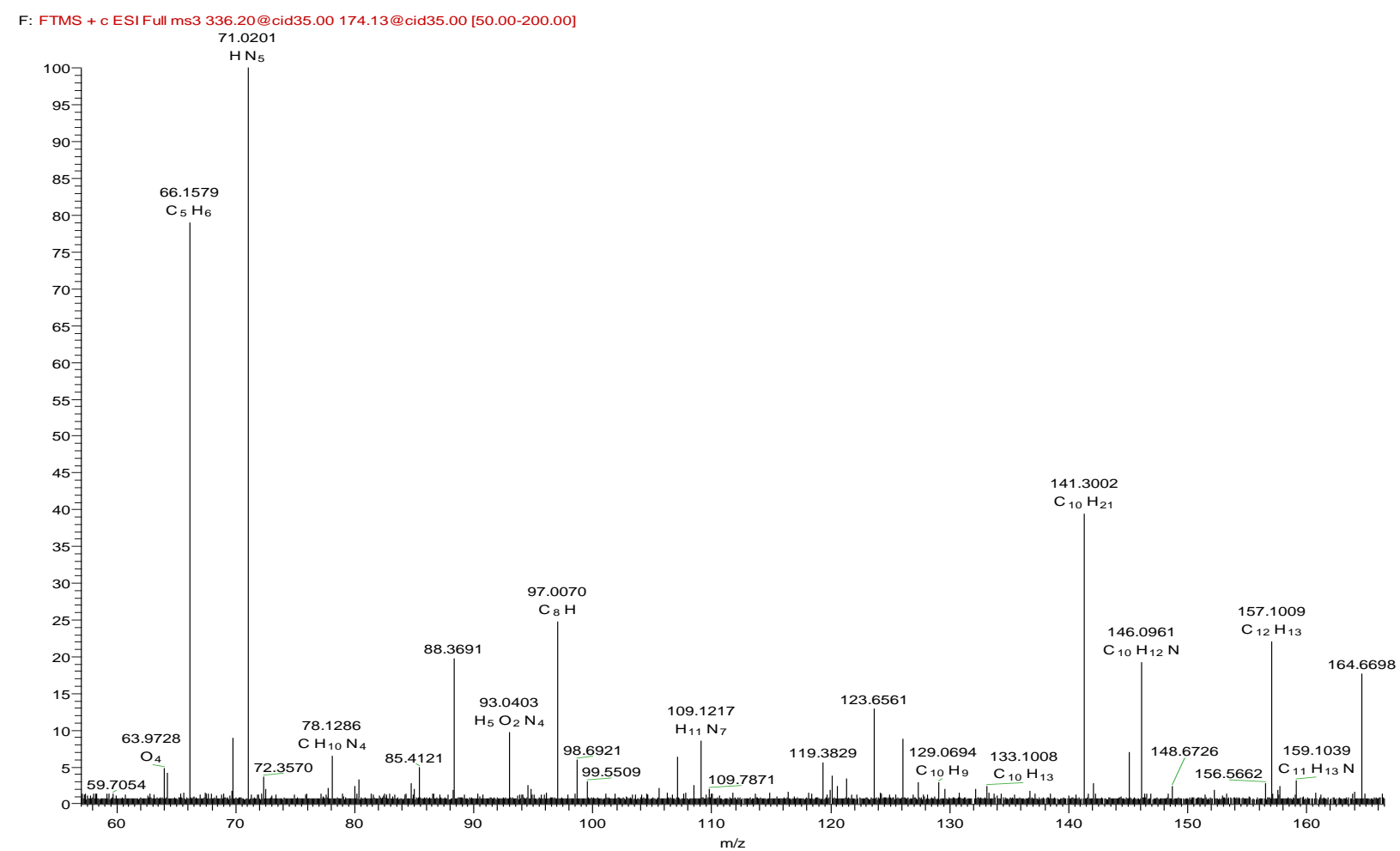

HRESI-MS spectrum of peak E

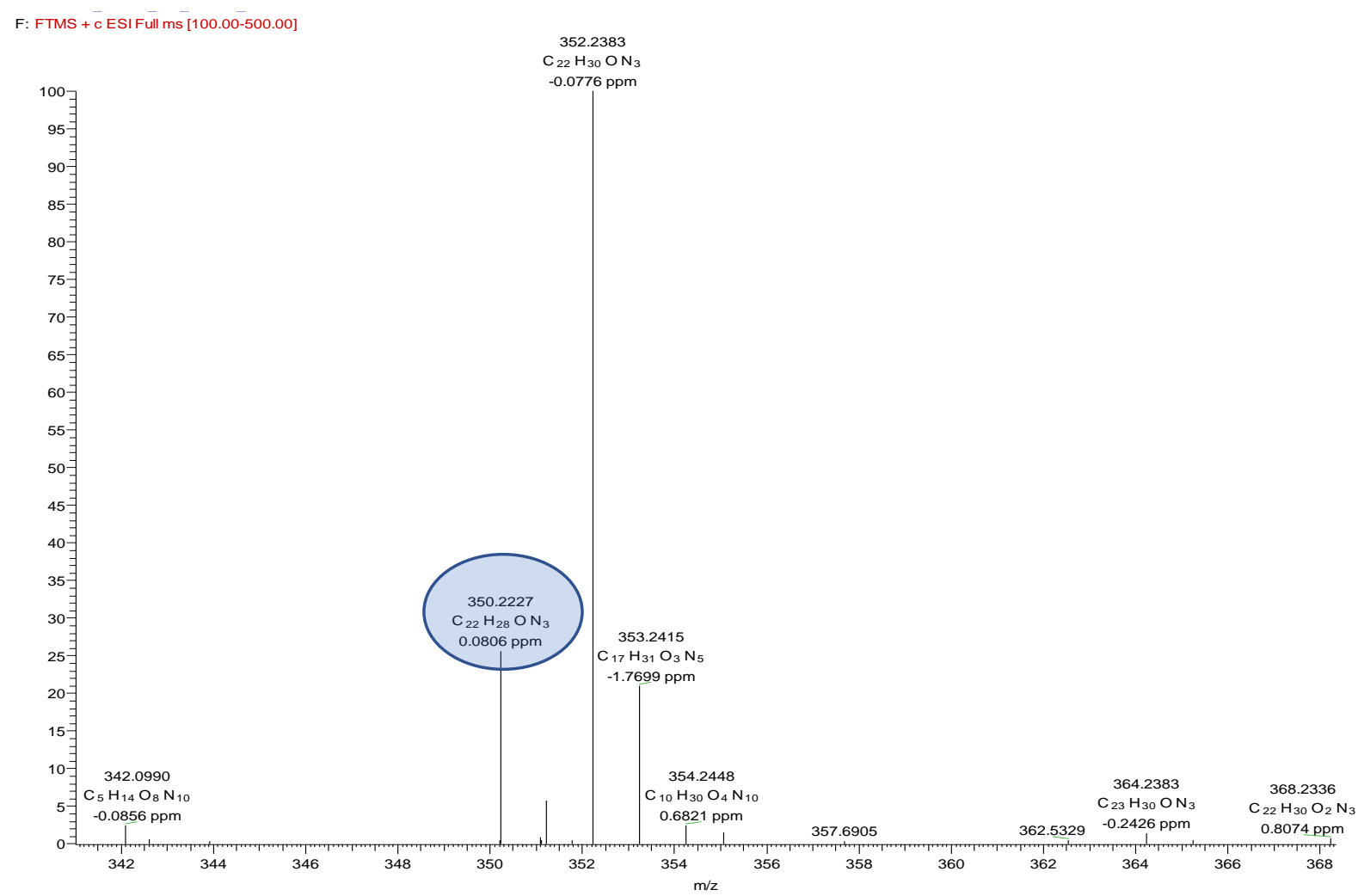




\section{HRESI-MS ${ }^{2}$ spectrum of peak E}

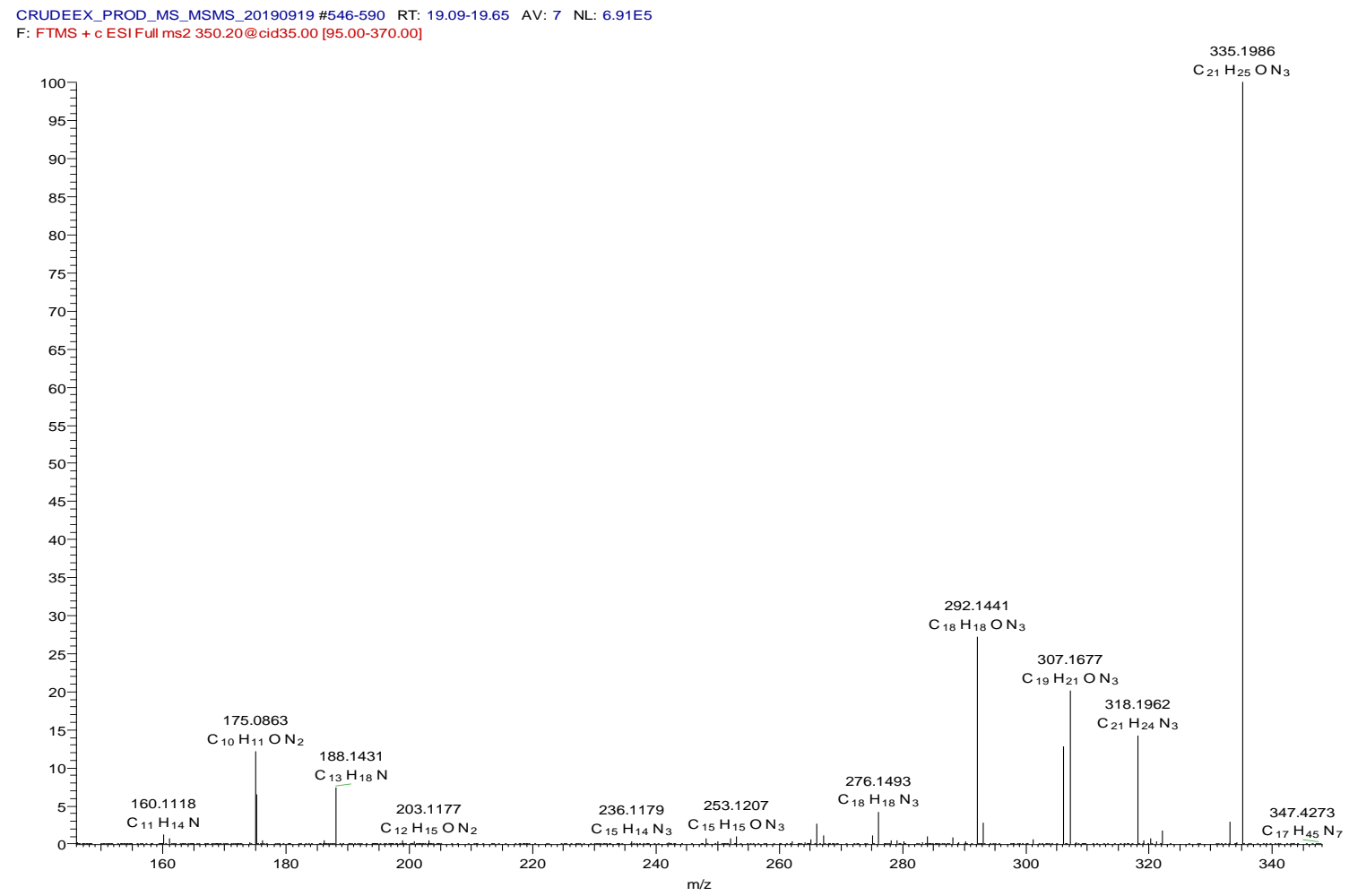

HRESI-MS ${ }^{2}$ spectrum of peak E - low $m / z$ portion.

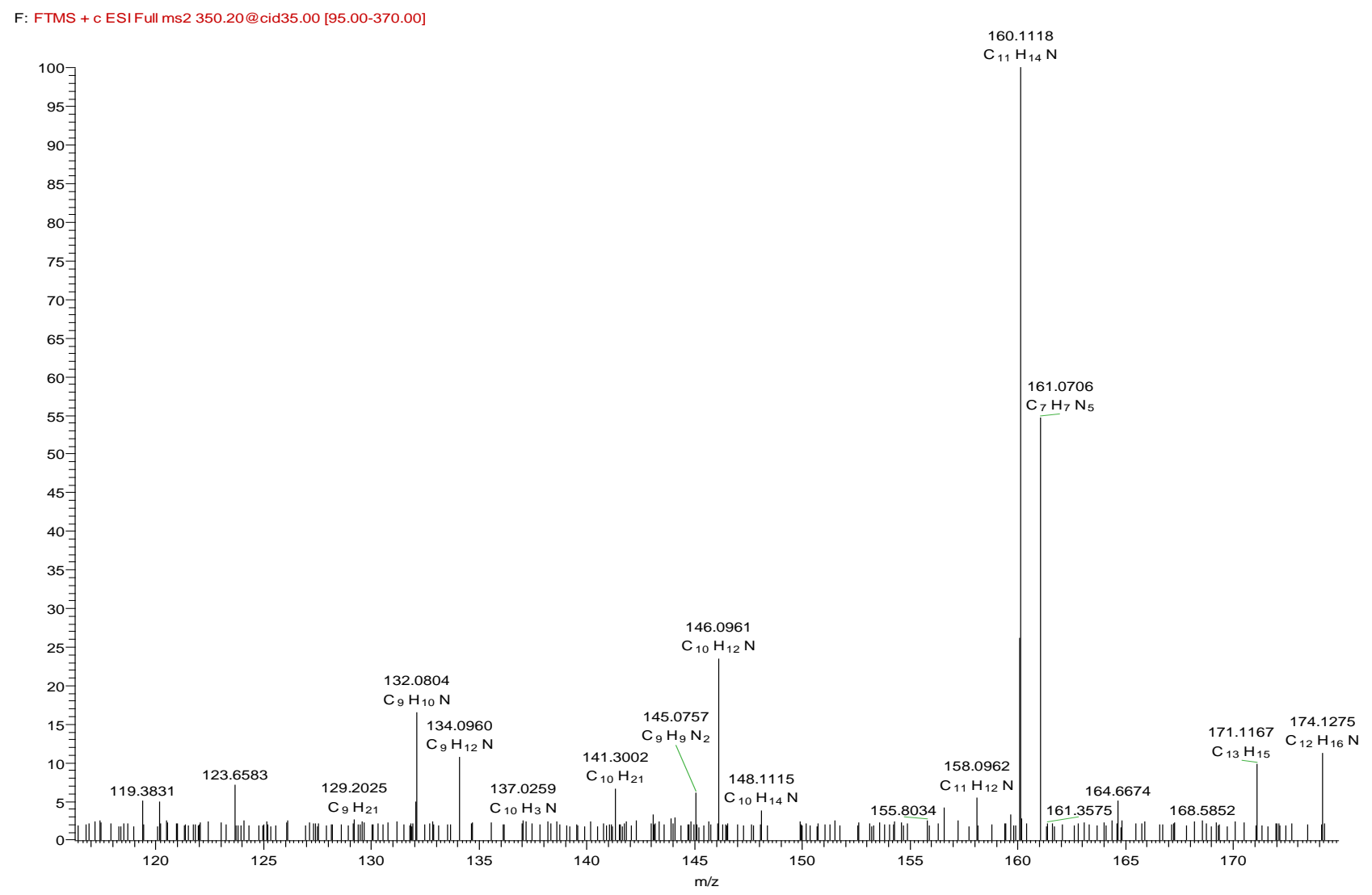


HRESI-MS $^{3}$ of peak E (from Fragment A, $m / z$ 188.1431)
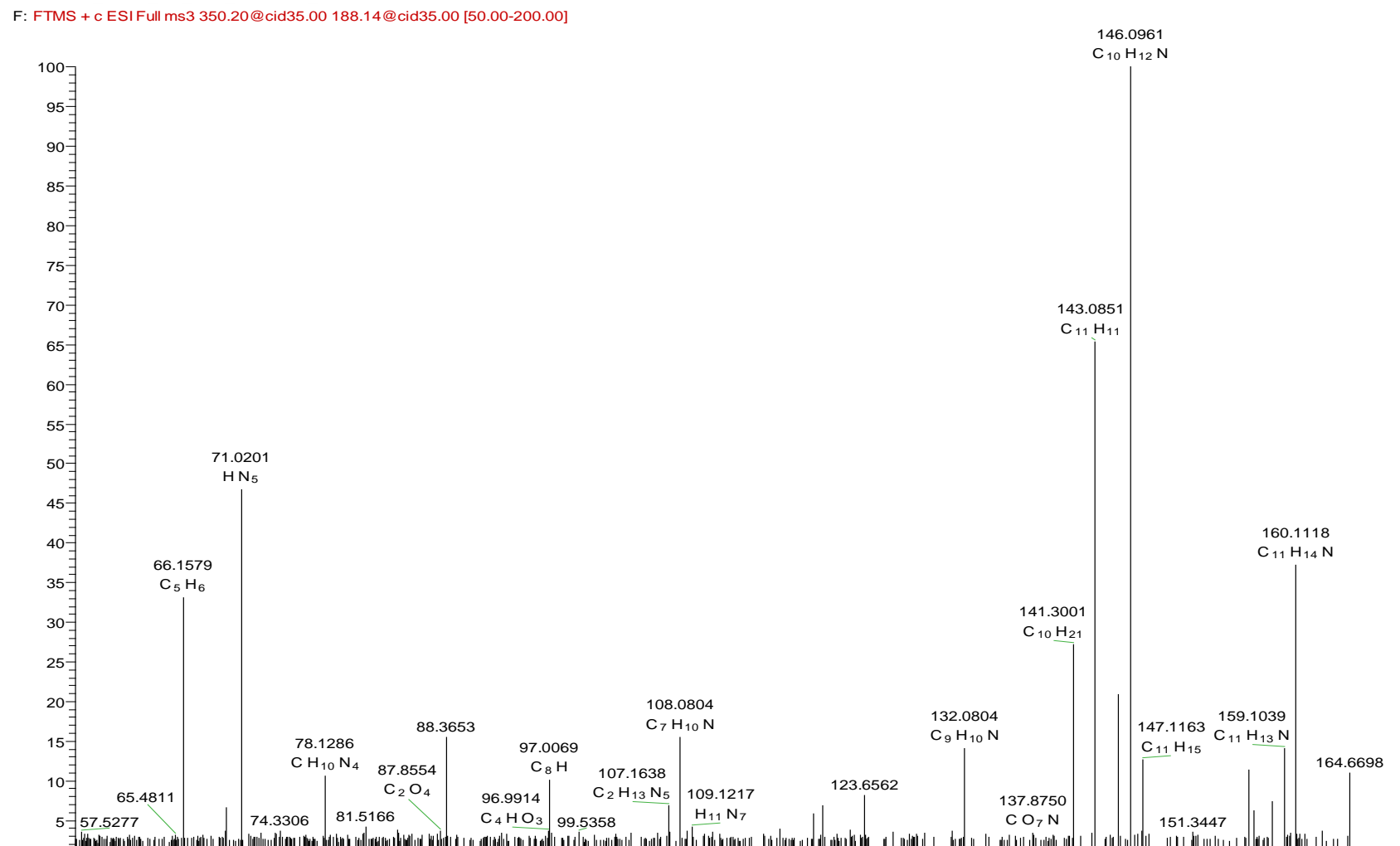

。 60 
Table S4. ${ }^{1} \mathrm{H}$ NMR Data of prodiginine pigments $\mathbf{1}, \mathbf{2}, \mathbf{3}$ and $\mathbf{4}$ from $V$. spartinae $3.6\left(\mathrm{CDCl}_{3}{ }^{\mathrm{a}}\right)$

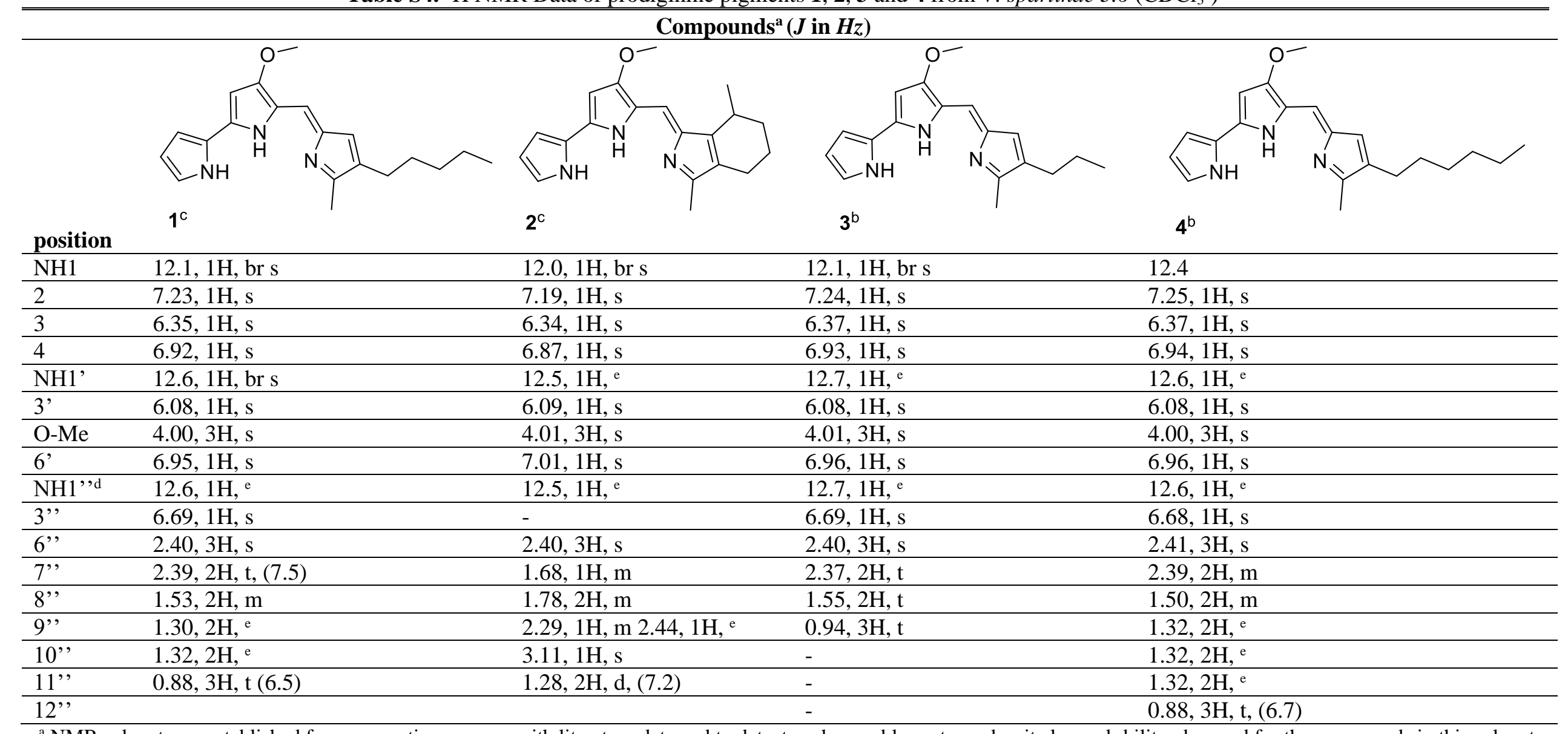

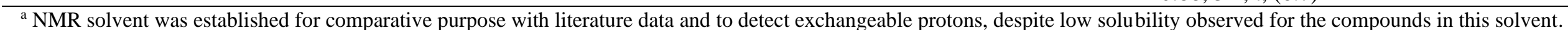

${ }^{\mathrm{b}}{ }^{1} \mathrm{H}$ signals were recorded on Varian $700 \mathrm{MHz} .{ }^{\mathrm{c}}{ }^{1} \mathrm{H}$ signals were recorded on Varian $400 \mathrm{MHz} .{ }^{\mathrm{d}}$ HPLC conditions furnished all compounds in their protonated form. ${ }^{\mathrm{e}}$

Overlapped with other signals. 